\title{
Casing Collapse Strength Analysis under Nonuniform Loading Using Experimental and Numerical Approach
}

\author{
Dongfeng Li, ${ }^{1,2}$ Fu Yu, ${ }^{3}$ Heng Fan $\mathbb{D}^{4},{ }^{4}$ Rui Wang, ${ }^{2}$ Shangyu Yang, and Xiangzhen Yan ${ }^{1}$ \\ ${ }^{1}$ College of Pipeline and Civil Engineering, China University of Petroleum (East China), Qingdao 266580, China \\ ${ }^{2}$ CNPC Tubular Goods Research Institute, Xi'an 710077, Shaanxi, China \\ ${ }^{3}$ Shanghai Key Laboratory for Digital Maintenance of Buildings and Infrastructure, Department of Civil Engineering, \\ Shanghai Jiao Tong University, Shanghai 200240, China \\ ${ }^{4}$ School of Electronic Engineering, Xi'an Shiyou University, Xi'an 710077, Shanxi, China \\ Correspondence should be addressed to Heng Fan; fan_h@xsyu.edu.cn
}

Received 22 February 2021; Revised 15 June 2021; Accepted 14 August 2021; Published 6 September 2021

Academic Editor: Jianguo Wang

Copyright (C) 2021 Dongfeng Li et al. This is an open access article distributed under the Creative Commons Attribution License, which permits unrestricted use, distribution, and reproduction in any medium, provided the original work is properly cited.

\begin{abstract}
Multistage fracturing is the main means of shale gas development, and casing deformation frequently occurs during fracturing of shale gas horizontal wells. Fracturing fluid entering the formation will change in situ stress nearby the wellbore. The changes of in situ stress are mainly reflected in the following two aspects: one is the increase of in situ stress and the other is the nonuniformity of in situ stress along the wellbore. And it is for this reason that the production casing is more likely to collapse under the nonuniform in situ stress load. According to the service conditions of production casing in shale gas reservoir, this paper studied the casing deformation and the collapsing strength subjected to the nonuniform loading by the experimental and numerical simulation method. The results show that under the condition of nonuniform loading, (1) the diameter variation rate of the casing reduces with the increase in the ratio of sample to tooling length. When the ratio is less than 3 , the casing collapse strength will be significantly reduced. And when the ratio is greater than 6 , the impact of sample length on casing collapse strength can be ignored. (2) The increase in the applied loading angle will decrease the diameter variation rate. When the loading angle increases from $0^{\circ}$ to $90^{\circ}$, the critical load value increases from $1600 \mathrm{kN}$ to $4000 \mathrm{kN}$. (3) The increase in load unevenness coefficient will rapidly decrease the casing collapse strength. When the load unevenness coefficient $n$ is 0.8 , the casing collapse strength reduces to $60 \%$, and when the load unevenness coefficient $n$ is 0 , the casing collapse strength reduces to $28 \%$. The findings of this study can help for better understanding of casing damage mechanism in volume fracturing of shale gas horizontal well and guide the selection of multistage fracturing casing type and fracturing interval design.
\end{abstract}

\section{Introduction}

Shale gas reservoirs have low porosity and low permeability. Generally, horizontal wells and large-scale multistage fracturing technology are used to improve the performance of reservoir production in an economical and effective way [1-4]. A shale gas well in Sichuan-Chongqing region has a drilling depth of $3500 \mathrm{~m}$, a horizontal section length of more than $1500 \mathrm{~m}$, and a fracturing displacement of about $12 \mathrm{~m}^{3} / \mathrm{min}$. The wellhead pressure of this well is about $80 \mathrm{MPa}$, and the production casing size is $\Phi 139.7 \times 12.7 \mathrm{~mm} / 125 \mathrm{~V}$, and the collapsing strength exceeds $160 \mathrm{MPa}$. In hydraulic fracturing operation, the bridge plug is often blocked in deflecting section or a horizontal section. The production casing is deformed, and the diameter is reduced by printing and calliper logs. Many studies [5-9] indicated that the rock formation is the reverse fault. When the fracturing fluid is injected into the formation, the magnitude of in situ stresses changes. In addition, as the horizontal in situ stress difference increases, the production casing cannot bear the nonuniform loading, resulting in the casing deformation [10-13]. It showed that the collapsing strength of casing under nonuniform loading is insufficient. Compared with that under uniform loading, the collapsing strength under nonuniform loading is reduced. 
The calculation formula for collapsing strength under uniform loading is provided by the American Petroleum Institute (API BUL 5C3) standard [12]. However, for tight reservoirs such as shale gas, the rock anisotropy and fracturing fluid injection lead to the complex in situ stress distribution [14-16]. The results show that the natural fracture length and dip angle have a great impact on the casing failure, which means that factors affecting collapsing strength of casing include nonuniform loading, the length of applied load, and loading angles. Cai et al. [17] carried out the test of casing collapsing strength under uniform loading by underwater strain and studied variation rules of casing strain with external loading. Pattillo et al. [18] analyzed the variation of casing collapse strength under the condition of a plane flattening test by the experiment and numerical simulation method.

It is found that the current research sets the shale gas reservoir and casing in full contact along the hole wellbore [19-22] and so that the partial contact is rarely studied, which is one of nonuniform loading distribution forms (in Figure 1, line $\mathrm{AB}$ is symmetry axis of the contact part between formation and casing). Thus, the variation rules of strain, deformation, and instability characteristics under nonuniform loading should be further studied. Lin et al. [23] studied casing deformation failure mechanism (yield strength 110ksi) under unidirectional loading through collapsing experiments. It was found that a point failure of the middle or outer wall of the casing rather than the yield point should be used as the basis of collapse failure. So, it is meaningful to determine casing collapse strength under nonuniform load by the experiential and numerical method.

According to the technical problem, this research carried out the casing deformation tests under different lengths, loading angles, and nonuniform loadings. The casing collapse failure and deformation characteristics for production casing $(\Phi 139.7 \times 12.7 \mathrm{~mm} / 125 \mathrm{~V})$ were analyzed in shale gas wells. In this paper, we firstly tested the influence of casing length and loading angle on casing collapse strength by the test method, and then we used the nonlinear buckling calculation method to carry out numerical experiments and got variation rule under different casing lengths, loading angles, and nonuniform loadings. This paper provided a method of analyzing casing deformation in actual service environment.

\section{Experimental Research on Nonuniform Loading}

2.1. Nonuniform Loading. In the condition of nonuniform loading, the load distribution is unevenly distributed along the casing outer wall. The stress distribution is expressed as

$$
p(\alpha)=p_{2} \sqrt{1-(1-n)^{2} \cos \alpha},
$$

where $n$ is the loading unevenness coefficient and can be expressed as $n=p_{1} / p_{2} . n=1$ corresponds to the uniform loading, and $n \neq 1$ corresponds to nonuniform loading. The

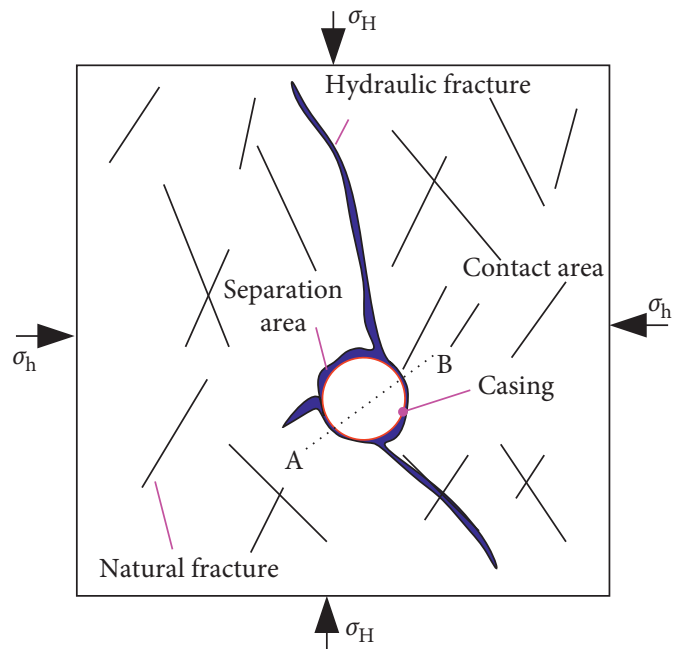

Figure 1: Contact model between formation and casing in hydraulic fracturing.

decrease in $n$ increases the unevenness of loading distribution. $p_{1}$ is the horizontal minimum principal stress; $p_{2}$ is the horizontal maximum principal stress; and $p(\alpha)$ is the internal loading along the angle $\alpha$.

Equations for uniform loading can be written as follows:

$$
p(\alpha)=p_{2} \text { or } p(\alpha)=p_{1} \text {. }
$$

There are two special cases. One is the loading applied on the part of casing circumference, that is, the loading surface is an arc surface, as shown in Figure 2(a). The other one is uniaxial loading, that is, the loading surface is a line (see Figure 2(b)). When $\alpha=180^{\circ}$, the casing is subjected to uniform loading, as shown in Figure 2(c).

2.2. Experimental Equipment. The experimental equipment is composite loading tester of 600t. According to the different experimental conditions, loading has been applied until the casing failure, and the stress-strain curve and loading value are collected and recorded. Six strain gauges are installed every $180^{\circ}$ on the casing circumference and every 50 or $100 \mathrm{~mm}$ in the axial direction, as shown in Figure 3. The sample installation is shown in Figure 4.

The sample size is $\Phi 139.70 \times 12.70 \mathrm{~mm} / 125 \mathrm{~V}$. It is assumed that the casing is an isotropic homogeneous elastomer, ignoring the effects of residual stress, ovality, wall thickness unevenness, and so on. The mechanical and chemical properties are identical during test analysis.

2.3. Experimental Scheme. In order to study the casing deformation rule under different lengths, different loading angles, and nonuniform loading, the experimental scheme is shown in Table 1.

For the experiment, the loading is uniformly increased, and the loading rate is $1 \mathrm{kN} / \mathrm{s}$. 


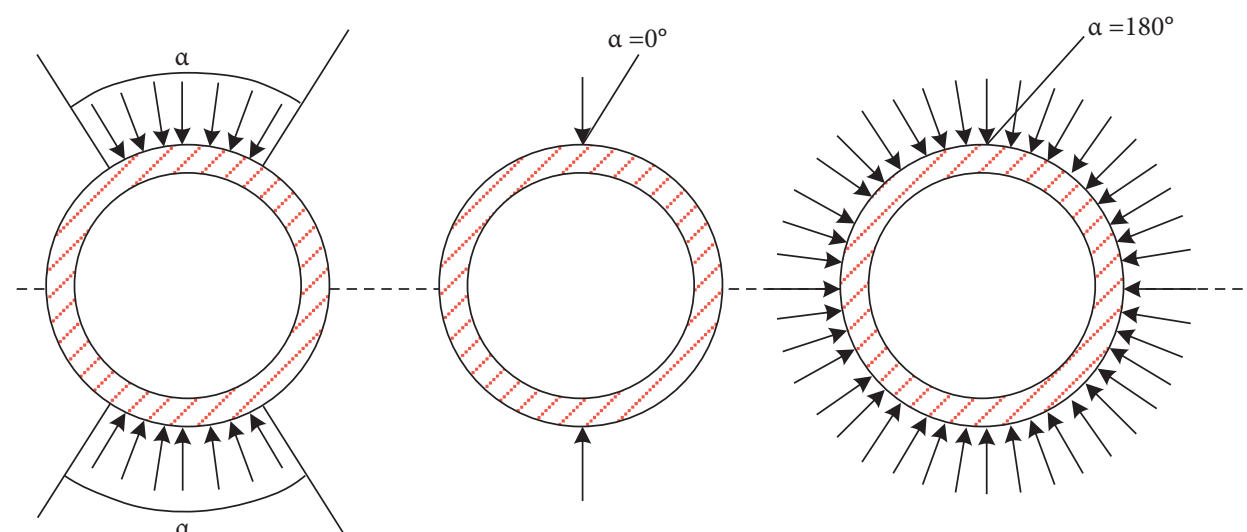

(a)

(b)

(c)

Figure 2: Schematic diagram for external loading action.

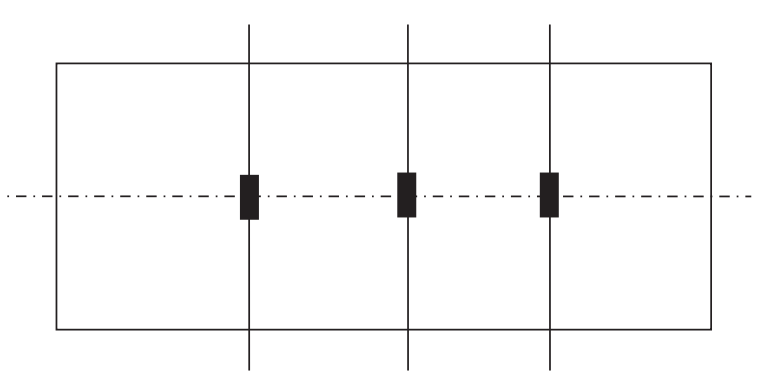

(a)

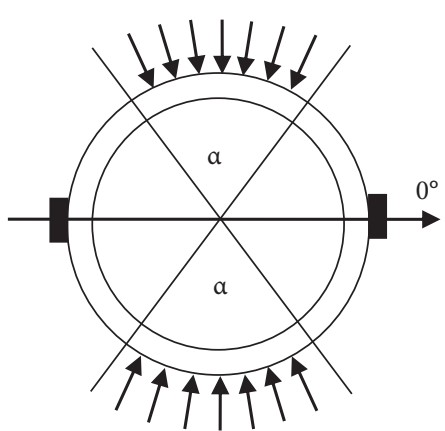

(b)

FIGURE 3: Schematic diagram for strain gauge installation: (a) axial direction; (b) casing circumference.

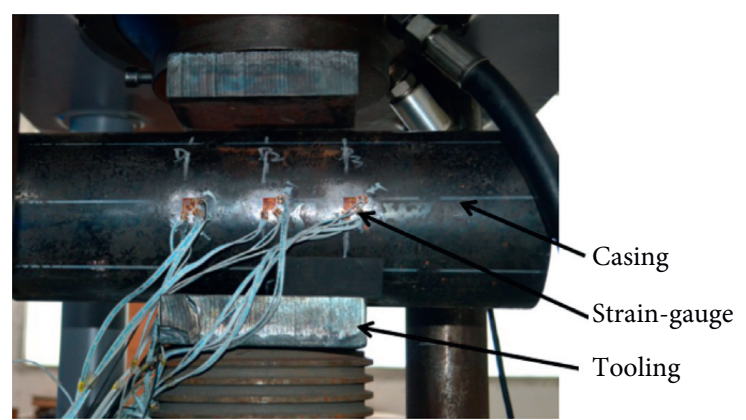

FIGURE 4: Schematic diagram for sample installation.

TABLE 1: Experimental scheme.

\begin{tabular}{ccccc}
\hline Group & Number & Loading angle $\left(^{\circ}\right)$ & Purpose & Notes \\
\hline & $1-1$ & & & Length: sample is 1D, tooling is 1D \\
Length: sample is 2D, tooling is 1D \\
Length: sample is 3D, tooling is 1D
\end{tabular}

Notes: $\mathrm{D}$ is casing diameter; $D=139.7 \mathrm{~mm}$. 


\subsection{Analysis of Experimental Results}

2.4.1. Impact of Sample Length on Collapsing Strength. Tooling length is $1 \mathrm{D}$, and the lengths of samples $1-1,1-2$, and 1-3 are $1 \mathrm{D}, 2 \mathrm{D}$, and $3 \mathrm{D}$, respectively. When the loading angle is 0 , the plane loading plane fails. This can be called a plane flattening test. The shape and tested results of sample 1-1 before and after tests are shown in Figure 5. The test results for three group samples are shown in Figure 6.

The sample experienced three stages of elasticity, yield, and instability in the failure process. When loading is $330 \mathrm{kN}$ and the diameter variation rate is $3.0 \%$, the yield occurs for sample 1-1, as shown in Figure 6. The diameter variation rate (the ratio of diameter variation value to the diameter for casing) of the casing does not increase linearly, as the load increases. For sample 1-2, yield occurs when loading is $670 \mathrm{kN}$, and the diameter variation rate is $3.1 \%$. For sample $1-3$, yield occurs when loading is $780 \mathrm{kN}$, and the diameter variation rate is $3.3 \%$. The yield loading increases with the increase in sample length; under the same loading, the diameter variation rate decreases with the increase in sample length. When the sample length is more than $3 \mathrm{D}$, the increasing trend of yield loading decreases. When the loading area is identical, the collapsing strength of casing increases with the increase in the sample length.

2.4.2. Impact of Loading Angle on Collapsing Strength. The tooling length is $2 \mathrm{D}$, the sample length is $7 \mathrm{D}$, and the loading angles are $0^{\circ}, 15^{\circ}, 30^{\circ}$, and $45^{\circ}$, respectively. These are called the curve flattening tests. For sample 2-2, the tooling shape and sample shape after testing and test results are shown in Figures 7 and 8 . The test results of sample 2-2 are shown in Figure 9.

As shown in Figure 9, the sample undergoes three stages of elasticity, yield, and instability. The yield load increases with the increase in $\alpha$, but the diameter variation rate decreases; under the same loading, the greater $\alpha$, the less of diameter variation rate; the larger of the loading area, the stronger of casing collapsing strength. Under nonuniform external loading, the casing collapse strength increases with the increase in $\alpha$.

\section{Finite Element Simulation Analysis}

3.1. Numerical Model Validation. According to the experiment results, the finite element simulation method was used to analyze collapse strength changes for different casing samples lengths from $1 \mathrm{D}$ to $7 \mathrm{D}$. Simulation parameters of casing are shown in Table 2. We assumed that casing is an ideal cylinder, and uneven wall thickness, the roundness of outer diameter, and ao on are not considered in the model. The radial dimension of the casing is much smaller than the axial length of the casing, which is simplified as a plane strain problem. Solid four nodes and 183 elements can be used for mesh generation, stresses, and deformation calculation. For sample 1-1, the finite element calculation results are shown in Figure 10, and the comparison of the experiment results and numerical simulation is shown in Figure 11.
As shown in Figures 10 and 11, the variation rate of casing diameter increases with the increase in loading. The maximum stress is located in the upper and lower of casing inner walls. The segment $(0 \mathrm{~A})$ of Figure 11 shows that the loading and diameter variation rate increases linearly, which belongs to the inelastic stage. The segment $(\mathrm{AB})$ of Figure 11 shows that when the diameter variation rate is greater than $3 \%$, the relationship between loading and diameter variation rate is a nonlinear increase. This belongs to the yield stage. The segment (BC) of Figure 11 shows that the diameter variation rate increases rapidly when it is greater than $10 \%$. However, this value is not sensitive to loading in the stage of instability. When the diameter variation rate continues to increase, the loading increases again, as the casing inner wall of the left and right sides begin to plying-up. This belongs to the strength strengthening stage. The experimental results are in good agreements with the results of finite element analysis.

For sample 2-3, the experimental and numerical simulation results are shown in Figure 12.

As shown in Figure 12, the numerical simulation results are in good agreement with the experimental ones. The diameter variation rate increases as the loading increases. The maximum stress appears on the upper and lower parts of the casing inner wall. In the initial loading stage, the diameter variation rate increases linearly with the increase in loading, and the sample is in the elastic stage. When the diameter variation rate is greater than $3 \%$, with the increase in loading, the diameter variation rate increases nonlinearly, and the sample is in the yield stage. When the diameter variation rate is greater than $10 \%$, the diameter variation rate increases rapidly. However, the loading increase rate is not significant, which is in the instability stage. When the diameter variation rate continues to increase, the casing inner wall begins to plying-up, and loading has an increasing trend again. This is in the stage of plastic strengthening.

3.2. The Influence of Different Sample Lengths on the Casing Collapse Strength. According to the experimental conditions of the first group, numerical simulation results can be obtained by changing the sample length, as shown in Figure 13. The diameter variation rate decreases at the contact surface. The casing deformation becomes smaller at the end of the sample with the increase in the sample length. However, when the sample is shorter, the end and contact surface of the sample have greater deformation.

The relationships between the diameter variation rate and the loading for the flattening test of different length samples are shown in Figure 14. The tooling length remains unchanged. As the length of the sample increases, the casing collapse strength (loading capacity) increases. When the sample length is less than or equal to $3 \mathrm{D}$, the casing collapse strength (loading capacity) will be significantly reduced. When the sample length is more than $3 \mathrm{D}$ but less than $6 \mathrm{D}$, casing collapse strength (loading capacity) gradually increases, and the increase rate gradually decreases. When the sample length is more than or equal to $6 \mathrm{D}$, the impact of 


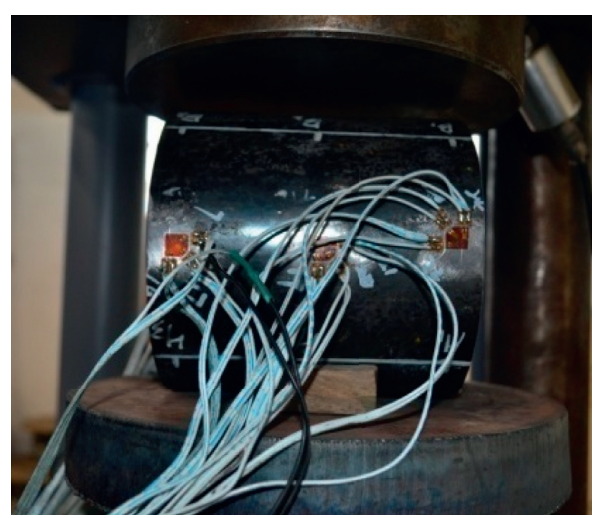

(a)

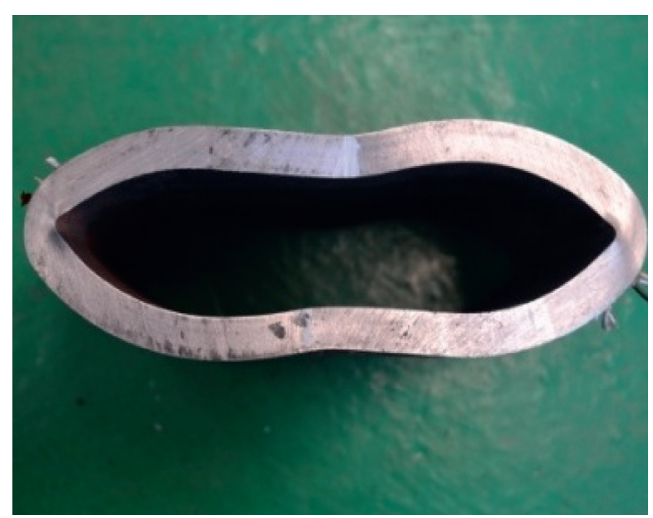

(b)

Figure 5: Installation diagram of sample 1-1 before the test (a) and shape of sample 1-1 after the test (b).

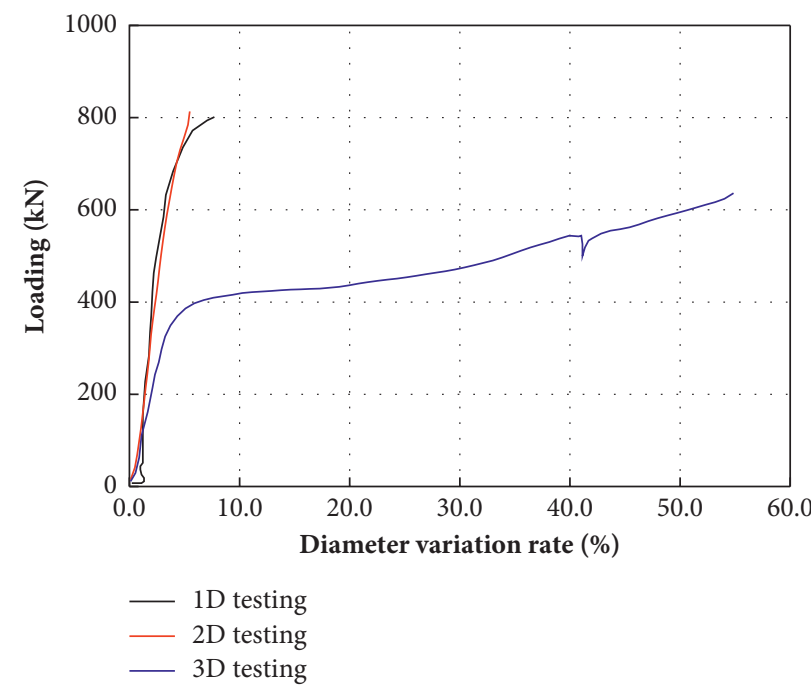

Figure 6: Loading versus diameter variation rate for different sample lengths.

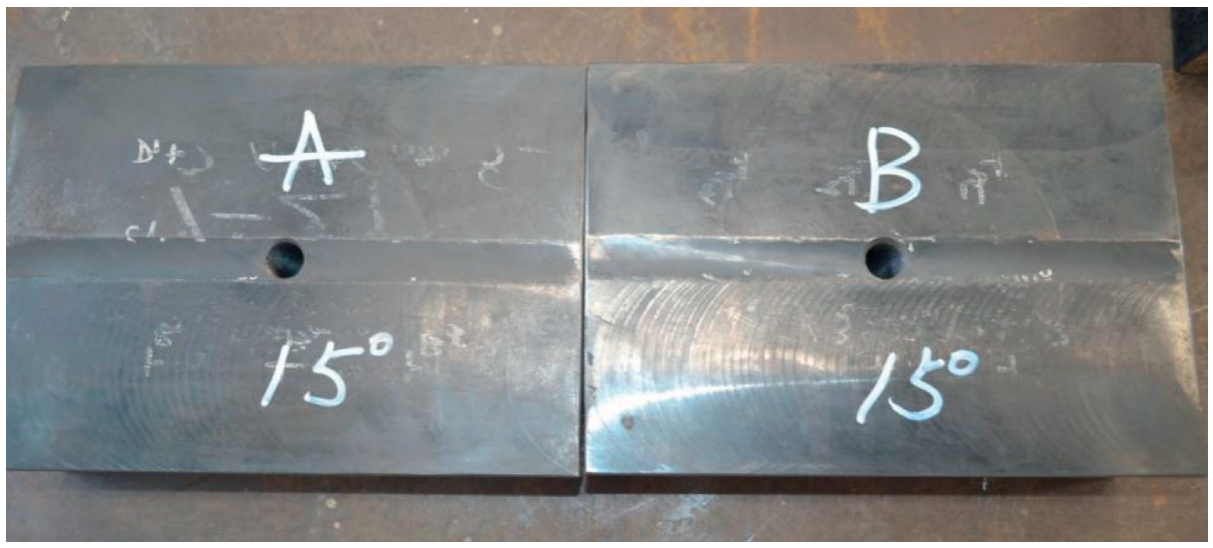

Figure 7: Tooling shape for $\alpha$ is $15^{\circ}$.

sample length on casing collapse strength (loading capacity) can be ignored.

The relationship between diameter variation rate and critical load for different length samples using the flattening test is shown in Figure 15. As the length of the sample increases, the critical loading and the diameter variation rate of instability increase, and the relationship between them is approximately proportional. It shows that the end effect is 


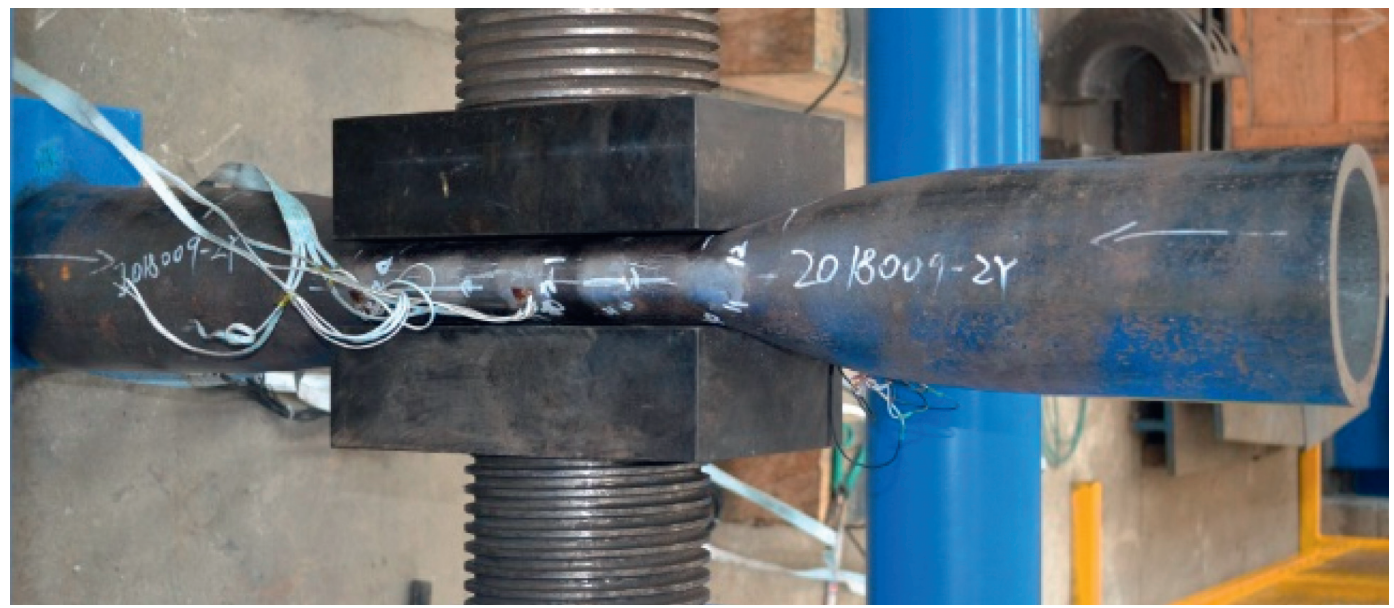

Figure 8: Sample shape after testing.

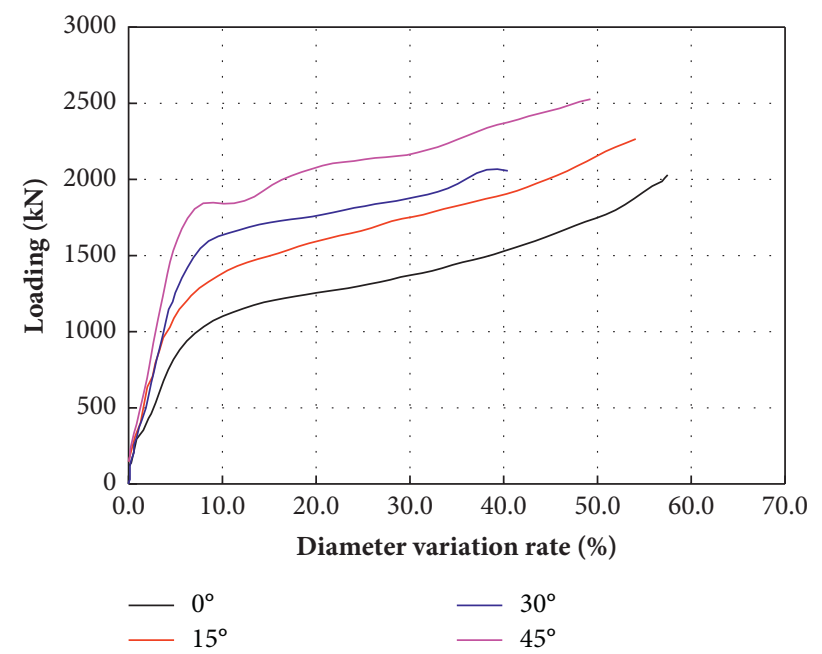

Figure 9: Loading versus diameter variation rate with different $\alpha$.

TABLE 2: Simulation parameter of casing 1-1.

\begin{tabular}{|c|c|c|}
\hline Parameter & Casing & Tooling \\
\hline Coefficient of friction & \multicolumn{2}{|c|}{0.1} \\
\hline Young's modulus & $200 \mathrm{GPa}$ & $360 \mathrm{GPa}$ \\
\hline Poisson's ratio & 0.3 & 0.3 \\
\hline Yield strength & $758 \mathrm{MPa}$ & \\
\hline Density & $7.87 \mathrm{~g} / \mathrm{cm}^{3}$ & \\
\hline
\end{tabular}

smaller when the sample is shorter. As the length of the sample increases, the end effect on the instability part is enhanced.

From the above results, it can give a suggestion that the spacing between fracturing points should be more than $6 \mathrm{D}$ in shale multistage hydraulic fracturing.

\subsection{The Influence of Different Loading Angles on the Casing} Collapse Strength. In order to eliminate the end effect, the ratio of sample length to tooling length has been set as $3.5: 1$. The finite element simulation method is used to analyze the influence of different loading angles on the casing collapse strength.
The relationships between the diameter variation rate and loading at different loading angles are shown in Figure 16. As the loading angle increases, the casing collapse strength (loading capacity) increases. The increase rate of loading capacity accelerates as the loading angle increases. This indicates that the casing collapse strength is enhanced. The results demonstrate that the collapse strength reaches the maximum under the uniform loading cases, that is, $\alpha$ is $180^{\circ}$. In the nonuniform loading cases, the casing collapse strength is reduced. In particular, when $\alpha$ is $0^{\circ}$, the collapse strength reduces the minimum value. Consequently, the casing is more likely to deform.

With the increase in loading angle, the critical loading increases, but the diameter variation rate decreases under the condition of instability, and the correlation between buckling loads and diameter variation rates are roughly inversely proportional, as shown in Figure 17. In the initial state, the loading surface fits the pipe body closely for different loading angles, which has certain constraints on the pipe body. However, there is no constraint on the plane load. For the same loading, the casing deformation becomes smaller as the loading angle increases. The greater the 


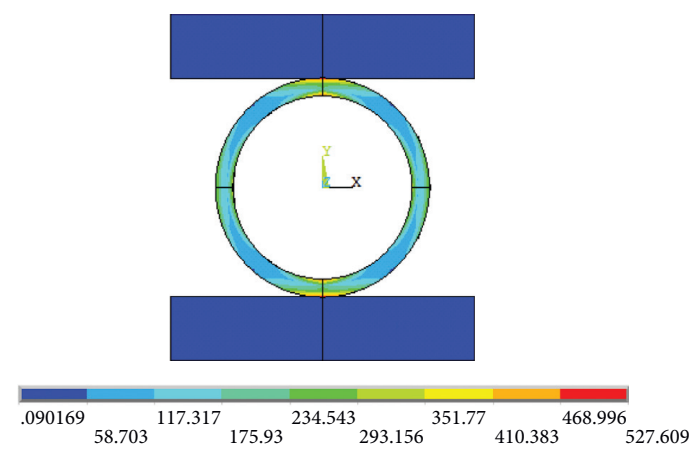

(a)

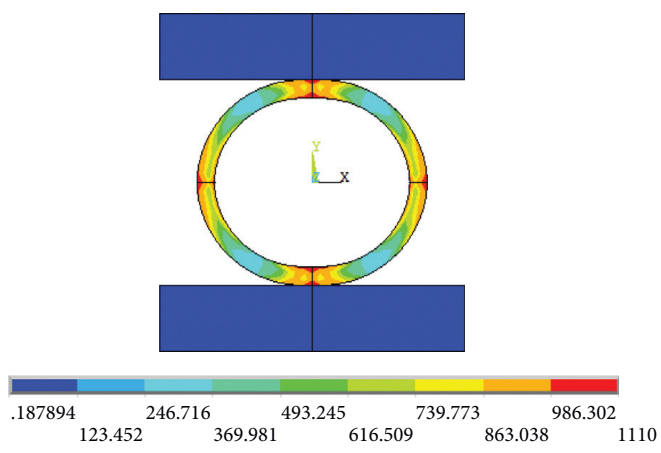

(c)

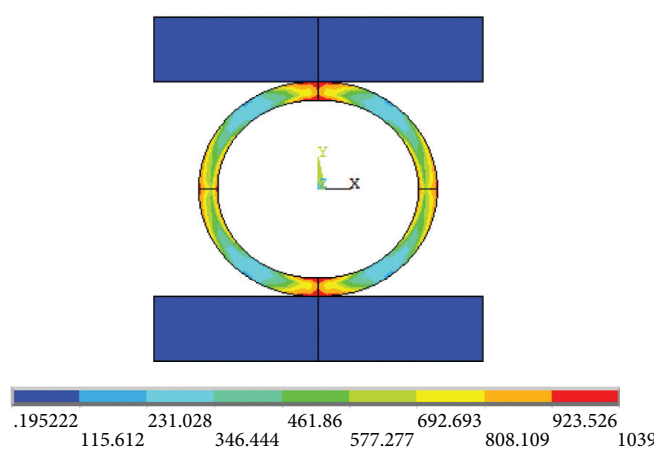

(b)

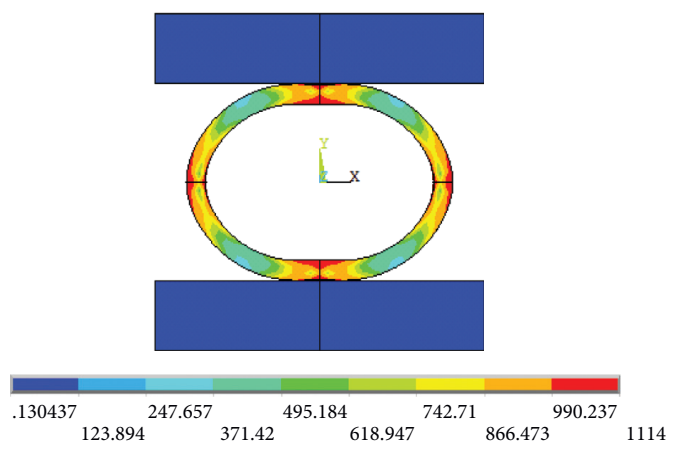

(d)

Figure 10: The finite element stress cloud diagrams for sample1-1. (a) Diameter variation rate is 1.15\%. (b) Diameter variation rate is 5.15\%. (c) Diameter variation rate is $10.0 \%$. (d) Diameter variation rate is $20.0 \%$.

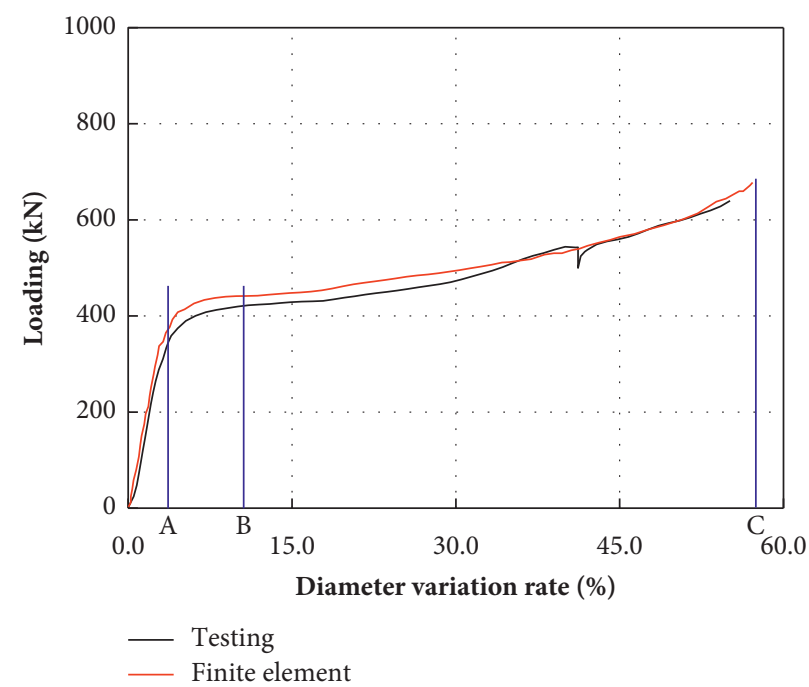

Figure 11: The comparison diagram of test results and finite element results for sample 1-1.

loading angle, the greater the restriction on the casing. In addition, the casing deformation is smaller as the loading angle increases.

There are two main reasons for the increase in collapse pressure with the increase in loading angle. (1) Under the same condition of casing stress, the increase in angle will cause the increase in contact area so that the total load level will increase. It can be seen from Figure 17 law that the load variation is not linear with different load angles. This means that there are other reasons for the increase in load. (2) The increase in the angle will change the stress state of the dangerous point in the casing. With the increase in the angle, the stress distribution in some areas of the casing is similar to that of the hydrostatic pressure. It means that the deviation stress of dangerous point in casing will decrease, so the collapse strength will be enhanced based on Mises strength theory. The curve in Figure 16 shows the strengthening phenomenon at the later stage, which is due to the increase 


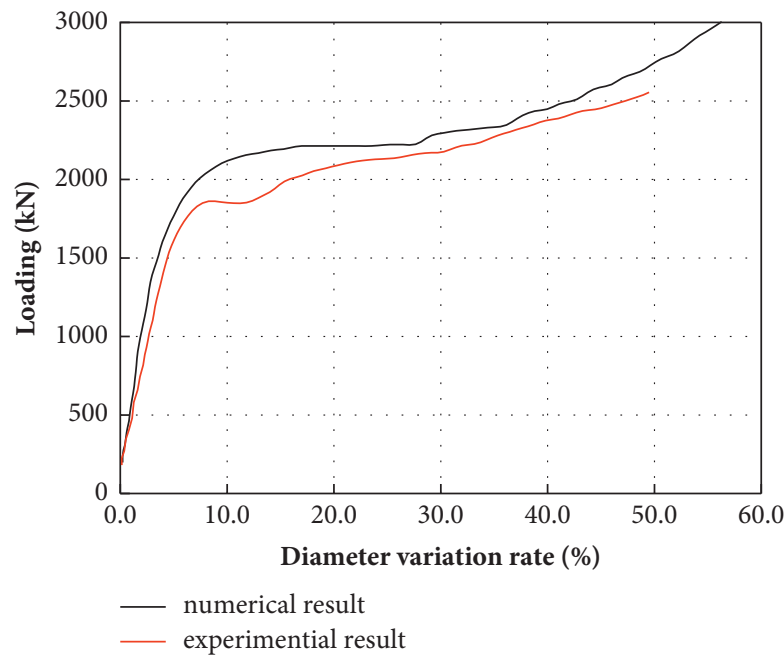

FIgURE 12: Results in comparison diagram of experiment and finite element analysis.

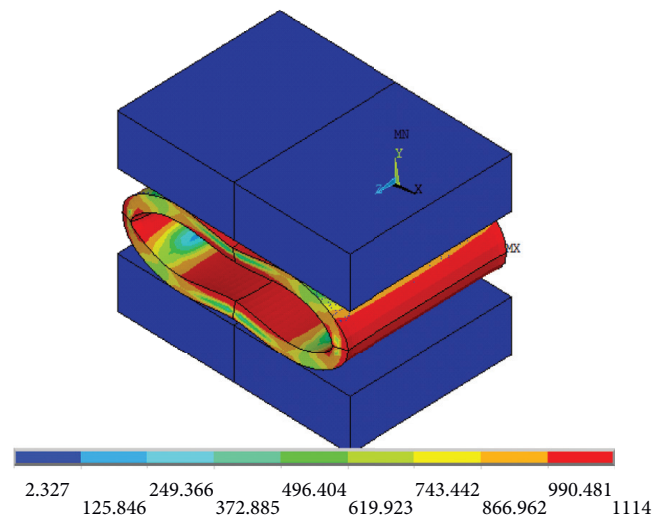

(a)

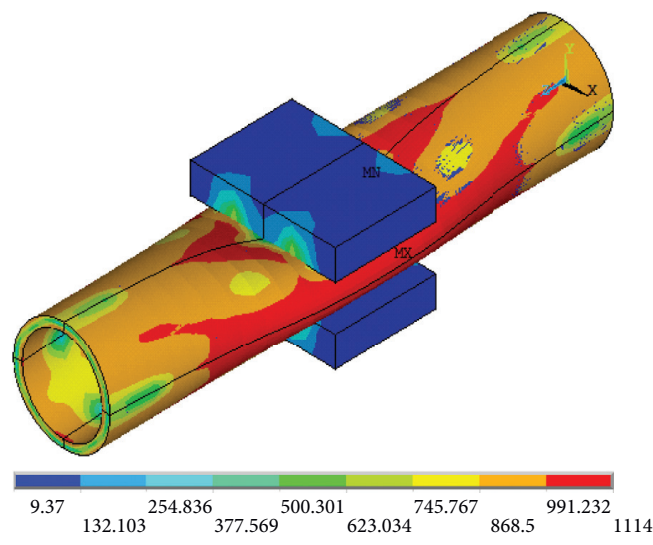

(c)

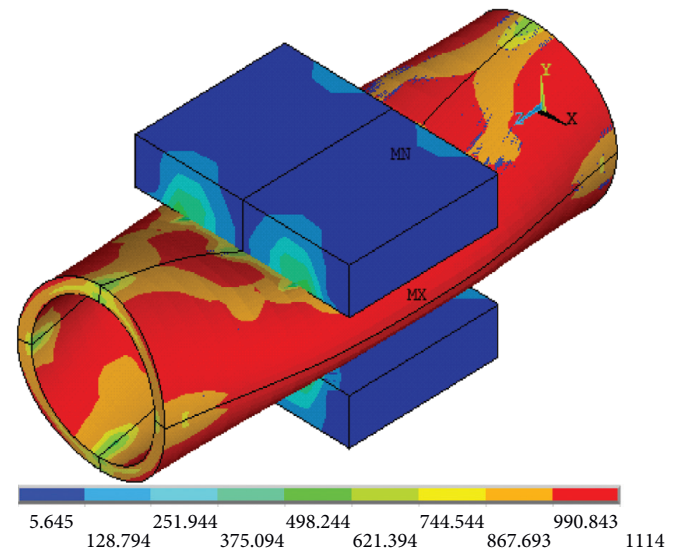

(b)

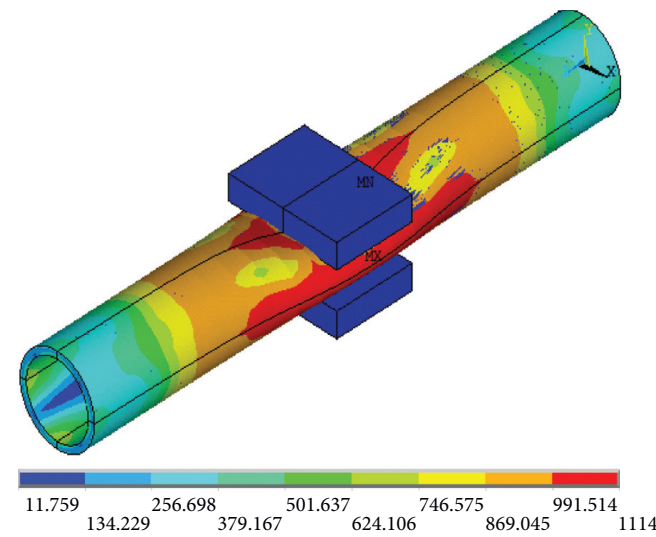

(d)

Figure 13: The finite element stress cloud diagram under different sample lengths: (a) the sample length is 1D; (b) the sample length is 3D; (c) the sample length is $5 \mathrm{D}$; (d) the sample length is $7 \mathrm{D}$. 


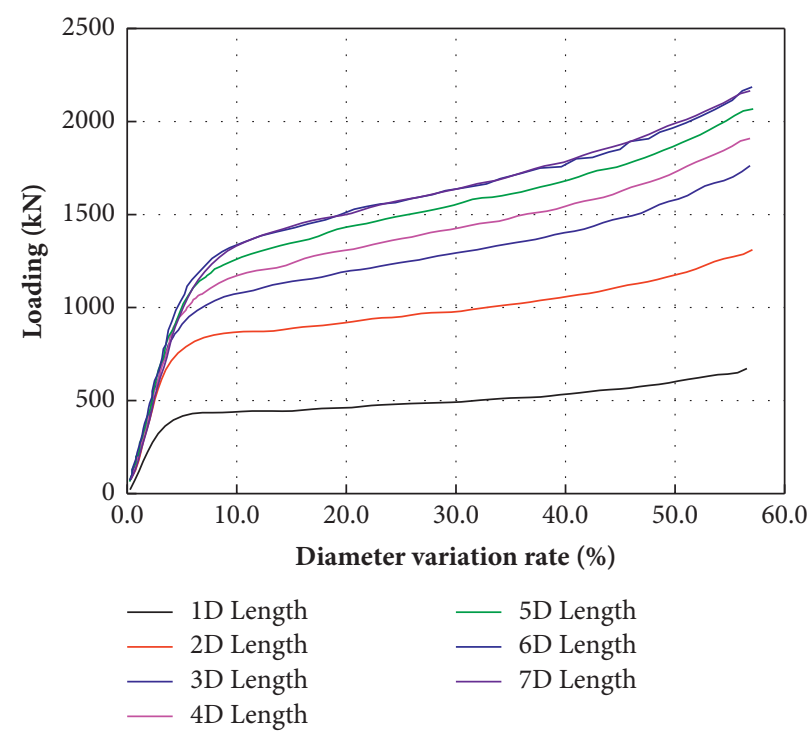

FIGURE 14: The relationship curve between the diameter variation rate and load for different length samples using the flattening test.

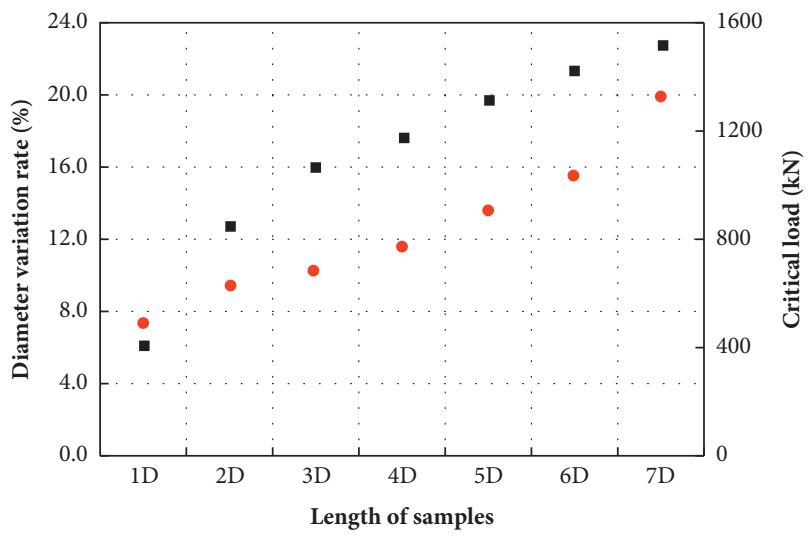

- Critical load

- Diameter variation rate

FIgURE 15: The relationship curve between diameter variation rate and critical load for different length samples from the flattening test.
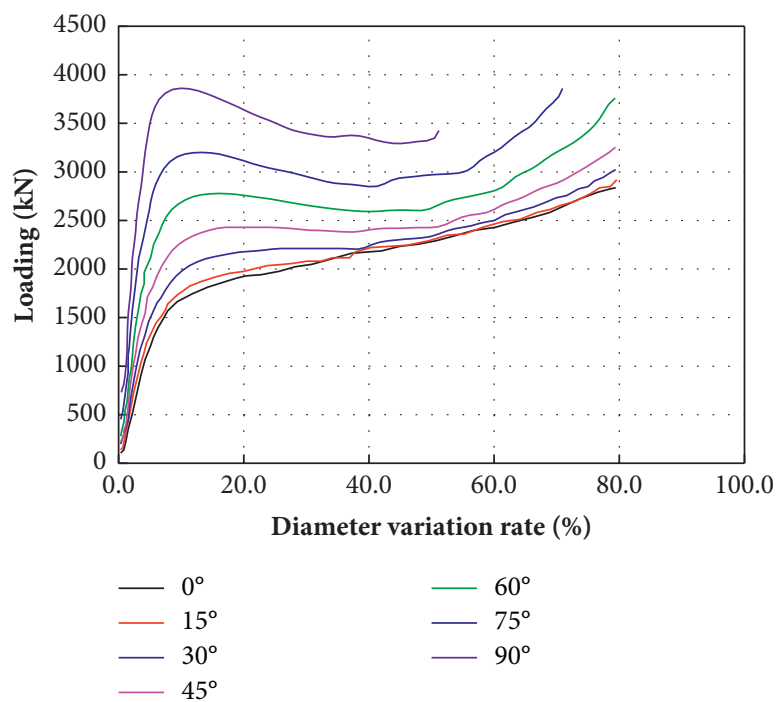

Figure 16: The relationship between simulated load diameter changes under different load angles. 


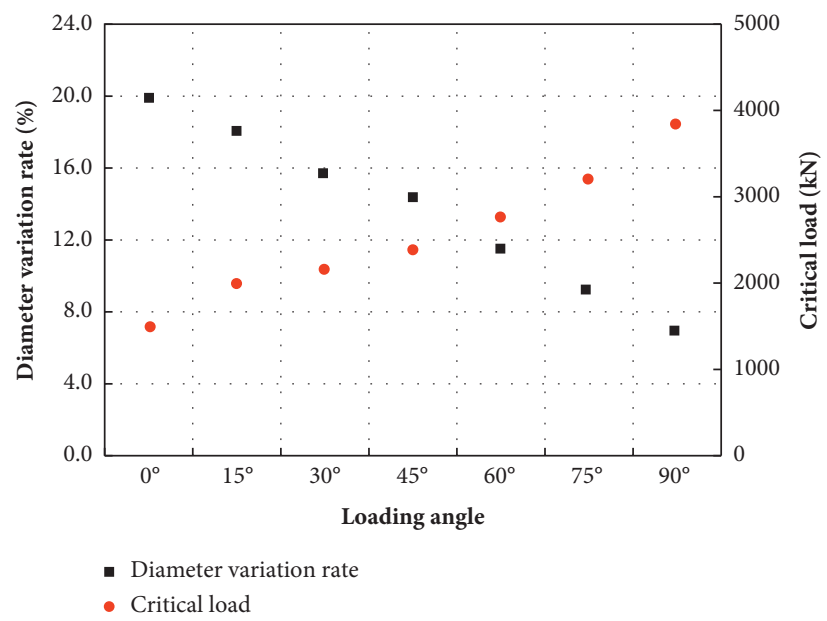

FIgURE 17: The relationship diagram between loading angle and critical load.

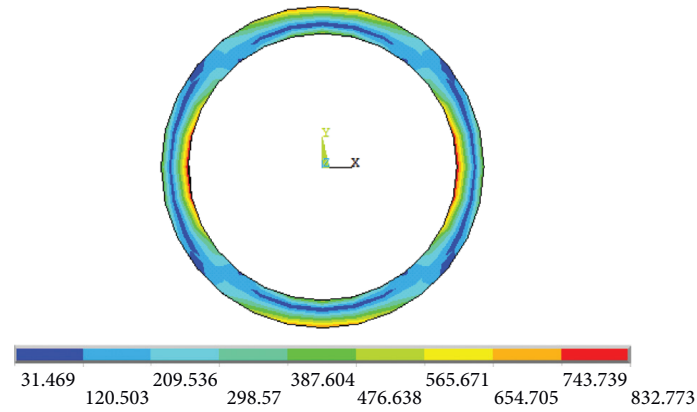

(a)

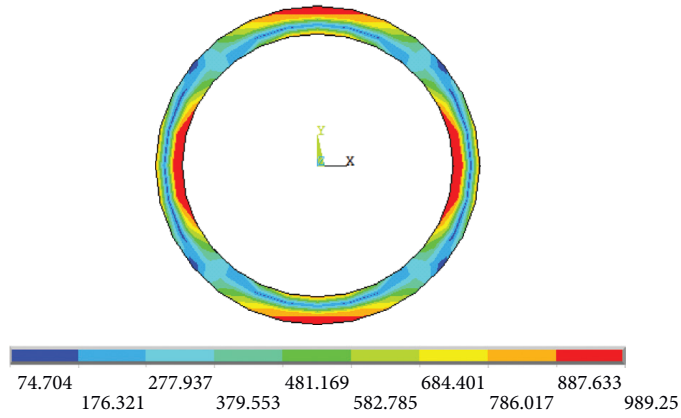

(c)

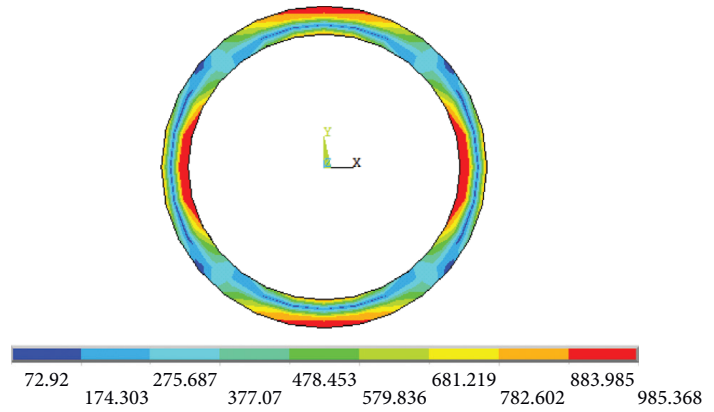

(b)

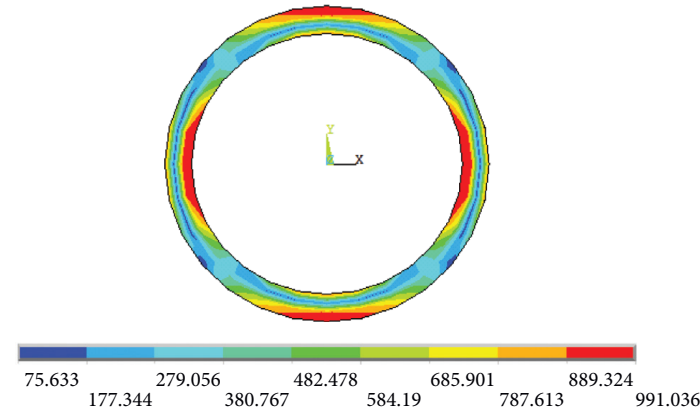

(d)

FiguRE 18: The finite element stress cloud diagram: (a) diameter variation rate is $0.7903 \%$; (b) diameter variation rate is $1.944 \%$; (c) diameter variation rate is $2.061 \%$; (d) diameter variation rate is $2.145 \%$.

in contact surface between the sample and tooling after casing deformation.

\subsection{The Influence of Load Unevenness Coefficient on Casing} Collapse Strength. Using a nonlinear buckling calculation method, the casing collapse strength is defined as the critical pressure of casing flattening or instability. When loading unevenness coefficient is $0.5\left(n=p_{1} / p_{2}=0.5\right)$, numerical simulation results are shown in Figure 18.
As shown in Figure 18, when the loading condition $\left(n=p_{1} / p_{2}=0.5\right)$ is applied, the stress of the casing inner wall in the short axis direction and the casing outer wall in the long axis direction is higher. Stress level and diameter variation rate increase as the loading increases. When the diameter variation rate reaches $2.0 \%$, the casing failure occurs. The pipe body of the long axis direction shows flattening deformation. On the other hand, the radial expansion deformation occurs in the short axis direction-the diameter variation rate of radial direction increases as the 


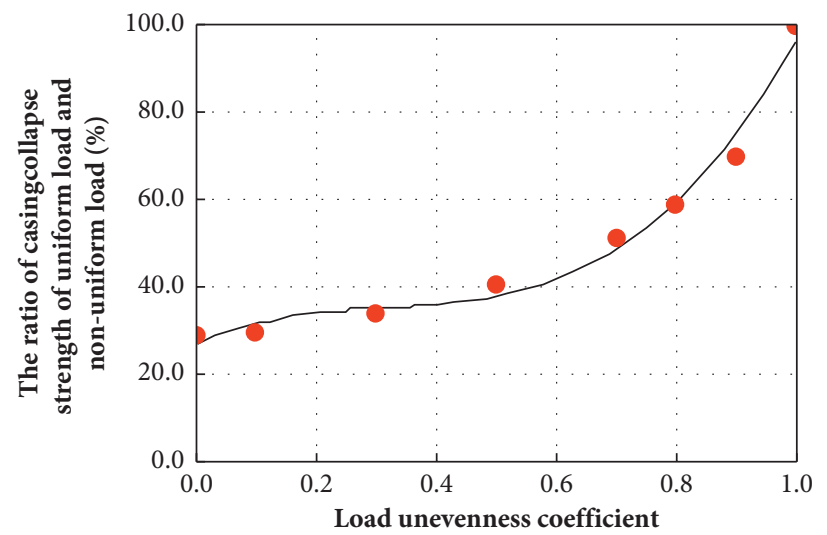

FIGURE 19: The law of casing collapse strength change with load unevenness coefficient.

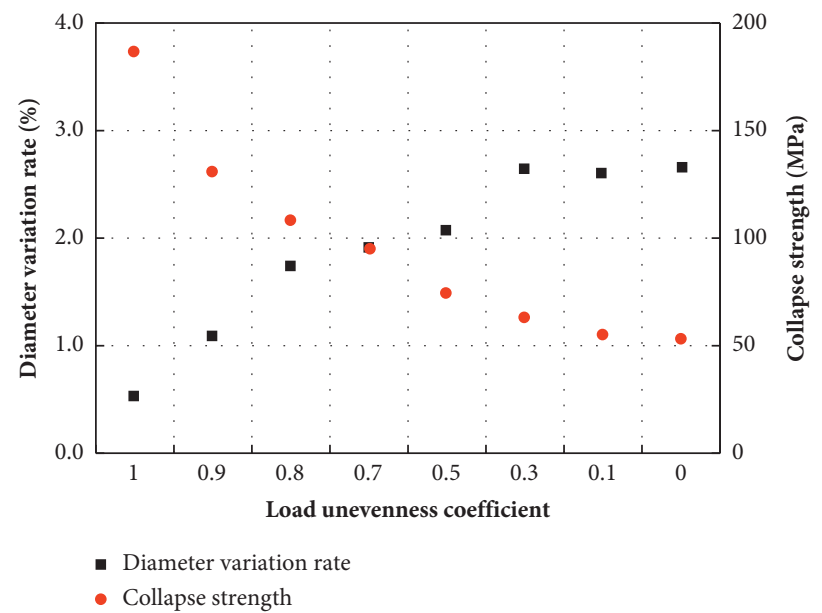

Figure 20: The relationship between the load unevenness coefficient, diameter variation rate, and collapse strength.

loading unevenness coefficient decreases. When the casing loading capacity is reached, the collapse failure occurs.

The relationship between load unevenness coefficient and the ratio of the casing collapse strength of uniform load and nonuniform load is shown in Figure 19. The uniform loading turns to nonuniform loading, and the casing collapse strength decreases rapidly. When the load unevenness coefficient $n$ is 0.8 , the casing collapse strength is about $60 \%$ for collapse strength of uniform load $(n=1)$. The load unevenness coefficient continues to decrease, and the reduction rate of casing collapse strength slows down. When the load unevenness coefficient $n$ is 0 , the casing collapse strength is about $28 \%$ for the casing collapse strength of uniform load $(n=1)$.

The model of load unevenness coefficient and the casing collapse strength is

$$
\begin{aligned}
y & =1.728 n^{3}-1.634 n^{2}+0.603 n+0.270, \\
p_{n} & =p_{1} y,
\end{aligned}
$$

where $y$ is the ratio of casing collapse strength for load unevenness coefficient $\mathrm{n} \in[0,1]$ separately and $p_{n}$ is the casing collapse strength for load unevenness coefficient $n$.
The relationship of load unevenness coefficient, diameter variation rate, and casing collapse strength is shown in Figure 20. As the load unevenness coefficient increases, the casing flexural strength of the casing decreases. When the casing failure occurs, the diameter variation rate increases. The relationship between casing collapse strength and diameter variation rate is roughly inversely proportional. When the load unevenness coefficient is small, the casing is more prone to failure and deformation. As the load unevenness coefficient increases, the casing is more difficult to deform and the load capacity is stronger.

\section{Conclusions}

For shale gas production casing deformation, it is suggested to consider nonuniform loading changes caused by fracturing for casing strength design. Based on the experimental and numerical results, the variation law and extremum for calculating the casing collapse strength for different loading unevenness coefficients are obtained.

(1) When the sample length is less than or equal to $3 \mathrm{D}$, the casing collapse strength is significantly reduced. 
When the sample length is more than $3 \mathrm{D}$ but less than $6 \mathrm{D}$, the casing collapse strength gradually increases as the sample length increases, but the increase rate is gradually slow down. When the sample length is more than or equal to $6 \mathrm{D}$, the effect of length on the loading capacity can be ignored.

(2) As the loading angle increases, the casing collapse strength and the increase rates of casing collapse strength increase. When the loading angle increases from 0 to 90 , the critical load value increases from $1600 \mathrm{kN}$ to $4000 \mathrm{kN}$.

(3) As the load unevenness coefficient decreases, the casing collapse strength reduces. When the load unevenness coefficient $n$ is 0.8 , the casing collapse strength reduces to $60 \%$, and when the load unevenness coefficient $n$ is 0 , the casing collapse strength reduces to $28 \%$.

\section{Data Availability}

No data were used to support this study.

\section{Conflicts of Interest}

The authors declare that there are no conflicts of interest.

\section{Acknowledgments}

This work was supported by the National Key Research and Development Program of China (2019YFF0217504).

\section{References}

[1] W. Yan, L. Zou, H. Li, J. Deng, H. Ge, and H. Wang, "Investigation of casing deformation during hydraulic fracturing in high geo-stress shale gas play," Journal of Petroleum Science and Engineering, vol. 150, pp. 22-29, 2017.

[2] Z. Chen, X. Liao, X. Zhao, X. Dou, and L. Zhu, "Performance of horizontal wells with fracture networks in shale gas formation," Journal of Petroleum Science and Engineering, vol. 133, pp. 646-664, 2015.

[3] K. Liu, D. Gao, Y. Wang, and Y. Yang, "Effect of local loads on shale gas well integrity during hydraulic fracturing process," Journal of Natural Gas Science and Engineering, vol. 37, pp. 291-302, 2017.

[4] L. Li, G. Wang, Z. Lian, L. Zhang, J. Mei, and Y. He, "Deformation mechanism of horizontal shale gas well production casing and its engineering solution: a case study on the huangjinba block of the zhaotong national shale gas demonstration zone," Natural Gas Industry B, vol. 5, no. 3, pp. 261-269, 2018.

[5] H. Yu, Z. H. Lian, and T. J. Lin, "Finite element analysis of failure mechanism of casing during shale gas fracturing," China Petroleum Machinery, vol. 42, no. 8, pp. 84-88, 2014.

[6] Z. Lian, H. Yu, T. Lin, and J. Guo, "A study on casing deformation failure during multi-stage hydraulic fracturing for the stimulated reservoir volume of horizontal shale wells," Journal of Natural Gas Science and Engineering, vol. 23, no. 3, pp. 538-546, 2015.

[7] C. Sugden, J. Johnson, M. Chambers, G. Ring, and P. V. Suryanarayana, "Special considerations in the design optimization of the production casing in high-rate, multistage-fractured shale wells," SPE Drilling \& Completion, vol. 27, no. 4, pp. 459-472, 2012.

[8] F. Yin and D. Gao, "Prediction of sustained production casing pressure and casing design for shale gas horizontal wells," Journal of Natural Gas Science and Engineering, vol. 25, no. 7, pp. 159-165, 2015.

[9] B. B. Dashtaki, G. R. Lashkaripour, M. Ghafoori, and N. H. Moghaddas, "Numerical modeling of casing collapse in Gachsaran formation in Sirri-E oilfield in Persian Gulf," Journal of Petroleum Science and Engineering, vol. 196, no. 1, Article ID 108009, 2021.

[10] G. A. Wang, Z. A. Chen, J. A. Xiong, and K. Yang, "Study on the effect of non-uniformity load and casing eccentricity on the casing strength," Energy Procedia, vol. 14, pp. 285-291, 2012.

[11] Y. Lin, K. Deng, D. Zeng, H. Zhu, D. Zhu, X. Qi et al., "Theoretical and experimental analyses of casing collapsing strength under non-uniform loading," Journal of Central South university, vol. 21, pp. 3470-3478, 2014.

[12] K. Deng, Y. Lin, W. Liu, D. Zeng, Y. Sun, and K. Li, “Equations to calculate casing collapse strength under nonuniform load based on new ISO model," Journal of Pressure Vessel Technology, vol. 138, no. 5, p. 54501, 2016.

[13] H. T. Li, J. G. Deng, W. Liu, Y. Li, and S. Lin, Research on Casing Deformation Failure Mechanism During Volume Fracturing for Tight Oil Reservoir of Horizontal Wells, U.S. Rock Mechanics/ Geomechanics Symposium, San Francisco, CA, USA, 2017.

[14] K. Liu, Y. Wang, D. Gao, X. Li, and Y. Zhang, "Effects of hydraulic fracturing on horizontal wellbore for shale gas," Acta Petrolei Sinica, vol. 37, no. 3, pp. 406-414, 2016.

[15] L. J. Gao, Z. L. Liu, L. Qiao, Z. Zhuang, and H. L. Yang, "Mechanism analysis and numerical simulation of casing failure in hydraulic fracturing of shale gas formation," China Petroleum Machinery, vol. 45, no. 1, pp. 75-80, 2017.

[16] X. Zhou, S. He, M. Tang, L. Fang, X. Zhou, and Z. Liu, "Mechanism of collapse failure and analysis of yield collapse resistance of casing under combined load," Engineering Structures, vol. 191, pp. 12-22, 2019.

[17] X. W. Cai, L. X. Gao, and L. Chang, "Study on underwater strain-measurement method as used in cading collapse test," Steel Pipe, vol. 38, no. 4, pp. 66-69, 2009.

[18] P. D. Pattillo, N. C. Last, and W. T. Asbill, "Effect of nonuniform loading on conventional casing collapse resistance," SPE/IADC Drilling Completion, vol. 19, no. 3, 2004.

[19] X. B. Zhao, J. J. Wang, and Y. Mei, "Analytical model of eellbore stability of fractured coal seam considering the effect of cleat filler and analysis of influencing factors," Applied Sciences, vol. 10, p. 1169, 2020.

[20] N. Kinoshita and Y. Inada, "Effects of high temperature on strength, deformation, thermal properties and creep of rocks," Journal of the Society of Materials Science, vol. 55, no. 5, pp. 489-494, 2006.

[21] W. M. Han, Y. F. Yan, and X. Z. H. Yan, "Research on the stress and deformation of casing in deep inclined salt rock formation," China Petroleum Machinery, vol. 47, no. 11, pp. 111-117, 2019.

[22] Y. Q. Yin, C. H. W. Chen, and P. E. Li, "Theoretical solution of stress distribution in casing, cement ring and formation," Theoretical and Applied Mechanics, vol. 38, no. 6, pp. 835-842, 2006.

[23] Y. H. Lin, K. H. Deng, D. Z. H. Zeng, J. K. Xiang, M. L. Wang, and W. Y. Liu, "The deformation law in the collapsingf process of $\mathrm{C} 110$ casing under non-uniform loading," Mechanical Science and Technology for Aerospace Engineering, vol. 34, no. 2, pp. 315-319, 2015. 